\title{
Design and implementation of intelligent audio- video interaction and control platform based on distributed architecture
}

\author{
Ruicai Huo*, Wei Huang, and Chao Liu \\ Beijing CSSC Information Technology Co. LTD, Beijing, 100094
}

\begin{abstract}
The traditional audio-video interaction mainly adopts matrix centralized processing technology with limited transmission distance and expansion. In application mode, the function of remote signal sharing and multi-screen linkage cannot be realized. Aiming at the above problems, an audio-video interactive platform based on distributed architecture is designed in the background of multi-type audio-video network information interconnection. This platform takes the distributed architecture as the core and combines the audio-video codec technology to build the distributed display control system, which can realize the arbitrary display and control of signals from many places and scenes, and satisfy the rapid sharing and forwarding and integrated call of audio-video information through the permission setting.
\end{abstract}

\section{Introduction}

Traditional audio-video interaction mainly matrices processing technology, in combination with display control use has many problems, such as: all input and output signals are concentrated on the stitching controller, all kinds of HDMI/DVI/VGA cable transmission distance is limited, such as data exchange share input/output interface card box is complete, the centralized processing technique on morphology determines the hardware scale once chosen, the late capacity upgrade is restricted. At the same time, once the system failure occurs in the centralized processing module, all the large-screen display and signal acquisition will be paralyzed, and no service can be provided in a short time. In the application mode, the traditional centralized processing technology can not complete the remote signal sharing and multi-screen linkage and other functions.

To solve above problems, combining with the current audio-video codec technology, audio-video display control business on the basis of traditional centralized display joining together, develop gradually form a distributed display control system, the system with distributed architecture as the core, will all audio-video signals through the acquisition of distributed input nodes in network access networks, realize stitching display through distributed output node in the output to the screen, which can realize sharing across regions in audio signal to each other, much larger set of concentrated visual controls, can be applied

*Corresponding author: huoruicai1985@163.com 
to scheduling command, information release, emergency consultation and collaboration at different scenarios.

\section{Application scenario and platform design}

\subsection{Application scenario}

Take a specific scene as an example, which involves multiple laboratory network environments in many places, and requires multiple experimental environments to directly carry out the display, communication, discussion and other activities aimed at business information and scene information. Due to the independent construction of each experimental environment, the system has great differences in interconnection, system interface, management platform, operation and maintenance, so the requirements of centralized display, intelligent interaction, unified management, unified operation and maintenance of audio-video business interaction of multiple laboratories cannot be realized.

\subsection{Platform design}

According to the above requirements of audio-video information interconnection in many experimental environments, this paper makes full use of the existing experimental network environment, and designs an audio-video intelligent interaction and control platform based on the network streaming media coding-decoding technology as the basic technical route and distributed architecture. The platform design is shown in the figure below:

\begin{tabular}{|c|c|c|c|c|c|}
\hline \multirow[b]{2}{*}{$\begin{array}{l}\text { Network } \\
\text { security }\end{array}$} & \multicolumn{4}{|c|}{ The presentation layer : Multimedia display terminal. } & \multirow[b]{2}{*}{$\begin{array}{c}\text { Services } \\
\text { portal }\end{array}$} \\
\hline & LED screen & Projection & $\begin{array}{c}\text { Interactive } \\
\text { terminal }\end{array}$ & LCD screen & \\
\hline & \multicolumn{4}{|c|}{ The interaction layer : Intelligent interactive svstem. } & \\
\hline \multirow[t]{2}{*}{$\begin{array}{c}\text { Data } \\
\text { security }\end{array}$} & $\begin{array}{l}\text { One-click } \\
\text { power on }\end{array}$ & $\begin{array}{l}\text { Identification } \\
\text { of perception }\end{array}$ & $\begin{array}{l}\text { Scheduling } \\
\text { management }\end{array}$ & $\begin{array}{l}\text { Interactive } \\
\text { operation }\end{array}$ & \multirow[t]{2}{*}{$\begin{array}{l}\text { Process } \\
\text { platform }\end{array}$} \\
\hline & \multicolumn{4}{|c|}{ The transport layer: Distributed hardware system. } & \\
\hline $\begin{array}{c}\text { Security } \\
\text { mechanism }\end{array}$ & $\begin{array}{l}\text { Input } \\
\text { nodes }\end{array}$ & $\begin{array}{l}\text { Output } \\
\text { nodes }\end{array}$ & $\begin{array}{c}\text { Control } \\
\text { nodes }\end{array}$ & $\begin{array}{l}\text { KVM } \\
\text { nodes }\end{array}$ & $\begin{array}{c}\text { System } \\
\text { monitoring }\end{array}$ \\
\hline \multirow[b]{2}{*}{$\begin{array}{l}\text { System } \\
\text { security }\end{array}$} & The Base layer & The network sys & & & \multirow{2}{*}{$\begin{array}{c}\text { Operational } \\
\text { service }\end{array}$} \\
\hline & $\begin{array}{c}\text { Core } \\
\text { devices }\end{array}$ & $\begin{array}{c}\text { Convergence } \\
\text { devices }\end{array}$ & $\begin{array}{l}\text { Access } \\
\text { devices }\end{array}$ & $\begin{array}{c}\text { Isolation } \\
\text { devices }\end{array}$ & \\
\hline
\end{tabular}

Fig. 1. The platform diagram.

\subsection{Network Architecture design}

Through the distributed architecture, all signal sources are integrated into a set of signal sources, and all display terminals (DLP, LED, LCD, projection, display, plug-in TV, etc.) are formed into a set of display terminal sets. Display terminal set can call any signal of signal source set for display and control. Thus according to the different display instructions form a multi - scene, multi - functional application mode. The network architecture design is shown in the figure below: 


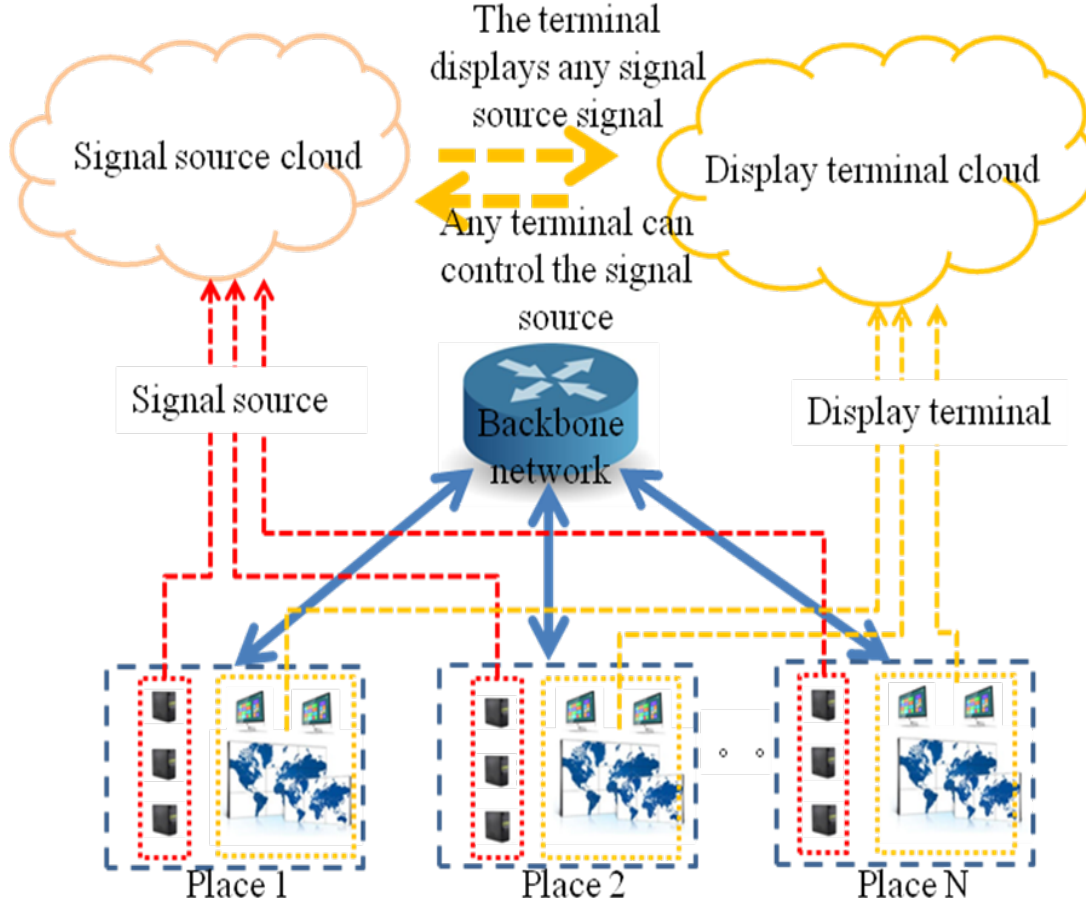

Fig. 2. The network architecture design diagram.

\subsection{Platform composition}

The main body of the platform is composed of several independent input, output nodes, control nodes, control terminals, etc., forming a distributed cluster. Data exchange between each node is conducted through a standard Ethernet switch, and all audio, video, image and control instructions are transmitted in an IP-based manner.

(1) Signal acquisition: Audio-video signals of all network environments are coded uniformly by input nodes and connected to the interconnection platform, which is integrated into a unified format.

(2) Signal output: All audio-video signals are decoded uniformly to different display terminals through output nodes, and corresponding output formats (such as resolution, interface type, etc.) can be configured according to the actual needs of different display terminals.

(3) System control: A unified control platform is built to achieve internal and interstation scheduling through the unified visual scheduling management of each touch screen control terminal and different authorization.

(4) Video display: multi-screen display can be carried out on a single display terminal, multiple signal Windows can be superimposed and combined, and the layout can be freely set and stored output; Output node can have its own splicing function, supporting multiscreen overlay, splicing roaming, arbitrary zoom of the screen and other functions.

(5) Audio signal: it can play with video synchronously, specify a certain way to play and audio broadcast on demand, etc. 


\subsection{Application scenario design}

The system adopts flat management and no hierarchy concept. Users are defined only according to the allocation of resource permissions, which can be finely allocated to each signal source and display screen. Users in this system are generally divided into platform administrator, laboratory administrator and ordinary user.

(1)Ordinary users: they have no operation rights, and can change the operation schedule of ordinary users if there is a need later.

(2)Lab manager: has the access to all signal sources in the lab and the on-screen access to all display terminals, and has no access to and on-screen access to other LABS.

(3)Platform administrator: has access to all signal sources of all laboratories and onscreen access to all display signals, and can authorize the definition of resource permissions for laboratory administrators and ordinary users.

\subsubsection{Scenario 1: Local scheduling management}

The local administrator is responsible for the retrieval of the local signal source. The local administrator owns the retrieval authority of all signal sources in the network environment and the on-screen authority of all signal terminals in the display environment, without the retrieval and on-screen authority of other network environments.

Control flow direction: The local administrator client issues scheduling control instructions through the distributed control node. The control node distributes control signals to the target input node according to the instructions, and the input node establishes a data flow link with the target output node in the local network according to the instructions.

Data flow link: Audio-video data flow link is: signal source $\rightarrow$ input node $\rightarrow$ local network switching $\rightarrow$ output node $\rightarrow$ display screen or sound.

The Scheduling management process is shown in the figure below:

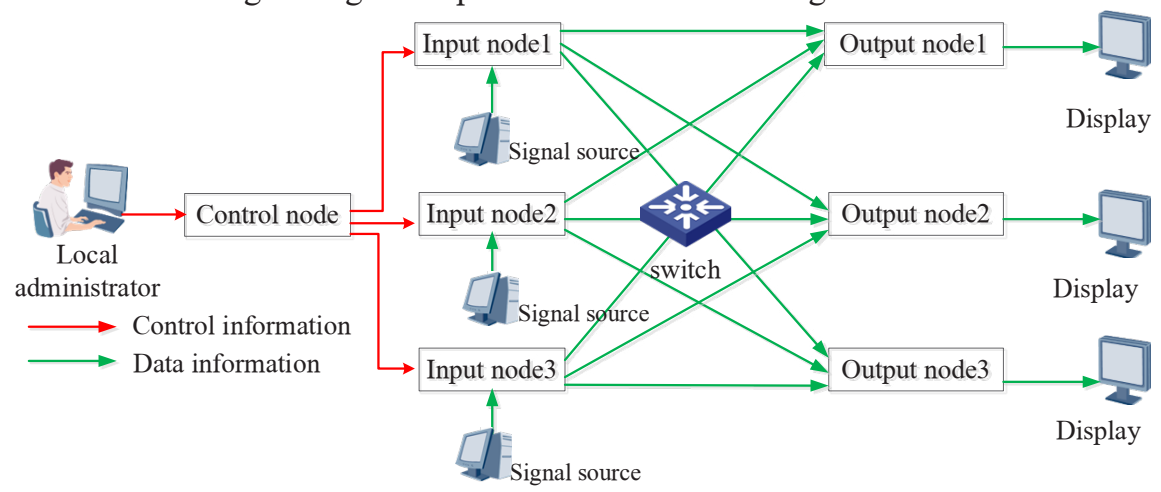

Fig. 3. The Scheduling management process diagram.

\subsubsection{Scenario 2: Remote scheduling management}

The scheduling of remote audio-video is operated by the platform administrator, who has the highest global authority. The sharing of signals between multiple network environments must be scheduled by the platform administrator, while the laboratory administrator and ordinary users have no operation authority. If necessary, the platform administrator can also temporarily authorize the laboratory administrator to execute. 
Control flow direction: The platform administrator sends scheduling instructions through the audio-video management master control server, and the input node establishes data flow links with the target output node in the local network according to the instructions.

Data flow link: Audio-video data flow link is: A ground signal source $\rightarrow$ A ground input node $\rightarrow$ trunk network switching $\rightarrow$ B ground output node $\rightarrow$ B ground display or sound.

The Scheduling management process is shown in the figure below:

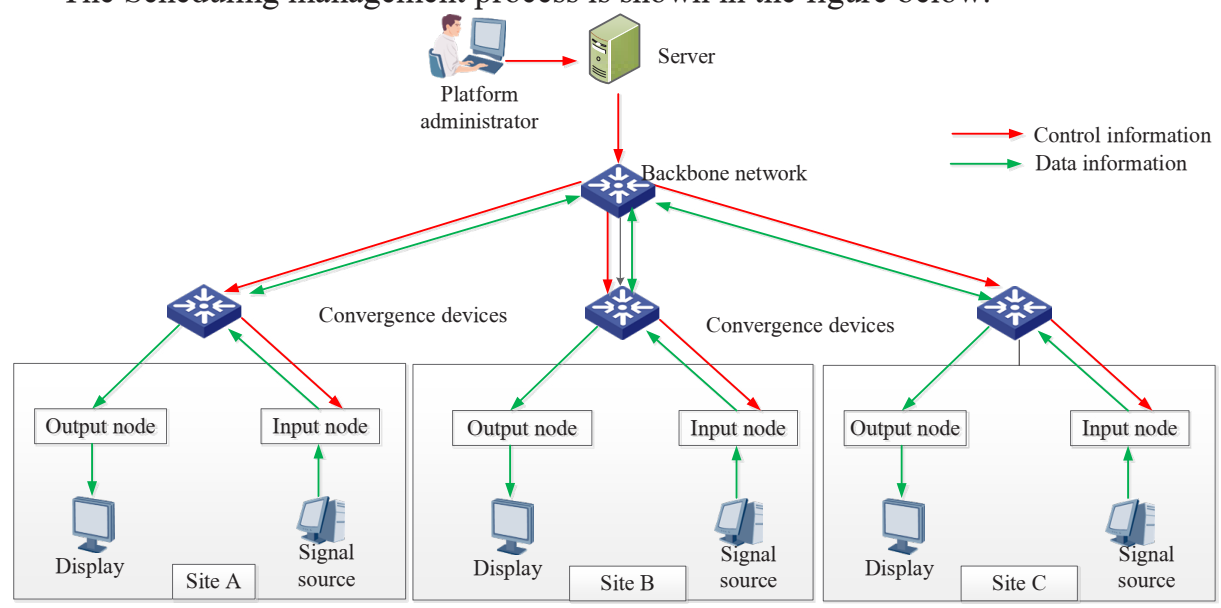

Fig. 4. The Scheduling management process diagram.

\section{Application effect}

Through the design and application deployment of distributed audio-video interaction and control platform, the cooperation and information sharing of diversified experimental simulation business can be realized, the comprehensive simulation deduction and command and dispatch ability can be improved, and the requirements of audio-video interaction under the new business mode can be met.

\section{References}

1. Jing Xue,Hongying Zhang,Fei Fan,Donglin Lai,Qingwei Li. Design of distributed Audio-video System based on double code stream[J]. The third Research Institute of China Electronics Technology Corporation,2020

2. Peng Peng. Discussion on the application of distributed visual seating System in command Center[J]. Nanjing Architectural Design and Research Institute Co. LTD,2020

3. Qi Yang. Signal interaction test of audio and video system based on IP architecture[J]. CCTV Technical Production Center Audio Department,2019

4. Jian Wang,Zhen Zhou,Wanchao Zhang. Audio and video network security isolation planning[J]. Wuhan Radio and Television Station,2017

5. Xin Ming Yao. Analysis of audio and video network and storage architecture of smart City[J]. Zhonganxiao Technology Co. LTD,2014 